\title{
Fotossenti: Um aplicativo para auxiliar em tratamentos psicológicos
}

\author{
Alternative Title: Fotossenti: An app to support on psychological treatments \\ Dárlinton Barbosa Feres Carvalho, Samuel Moreira Abreu Araújo \\ darlinton@acm.org, samucacesa@yahoo.com.br \\ Universidade Federal de São João del Rei (UFSJ) \\ Departamento de Ciência da Computação \\ São João del Rei, MG, Brasil
}

\begin{abstract}
RESUMO
Este artigo apresenta um inovador sistema de informação para auxiliar em tratamentos psicológicos por meio de fotos feitas pela câmera de smartphones ou tablets, em que se cria um novo canal de comunicação entre paciente e terapeuta por meio do aplicativo proposto Fotossenti. A proposta deste aplicativo é ajudar na geração e gestão de informações para serem trabalhadas nas sessões de terapias do paciente, que poderiam passar despercebidas no contato tradicional com o terapeuta. Neste artigo apresenta-se uma breve fundamentação teórica acerca de Tecnologias de Informação e Comunicação (TICs) aplicadas à Saúde, especialmente aquelas voltadas para psicologia e consideradas no desenvolvimento deste trabalho, bem como características ímpares do Fotossenti, uma avaliação do aplicativo feita por especialista da área de psicologia e, por fim, os desafios e oportunidades encontrados. A conclusão reitera a importância do desenvolvimento e uso de novas TICs, em especial novos sistemas de informação, no campo da saúde psicológica, e coloca o aplicativo Fotossenti como um instrumento para contribuir na geração de informações para o tratamento psicológico, e consequentemente nas decisões tomadas pelo terapeuta aumentando o benefício do tratamento.
\end{abstract}

\section{Palavras-Chave}

sistema de informação para tratamento psicológico, tratamento psicológico orientado a fotos, m-saúde, e-saúde.

\begin{abstract}
This paper presents a novel information system to assist in psychological treatments through pictures taken by the camera of smartphones or tablets, creating a new communication channel between patient and therapist by the use of the proposed application Fotossenti. The purpose of this application is to help in the generation and management of
\end{abstract}

Permission to make digital or hard copies of all or part of this work for personal or classroom use is granted without fee provided that copies are not made or distributed for profit or commercial advantage and that copies bear this notice and the full citation on the first page. To copy otherwise, to republish, to post on servers or to redistribute to lists, requires prior specific permission and/or a fee.

SBSI 2015, May 26th-29th, 2015, Goiânia, Goiás, Brazil

Copyright SBC 2015. information to be considered on the patient's therapy sessions, which could go unnoticed in the traditional way. This paper presents a brief theoretical foundation on Information and Communication Technologies (ICTs) applied to Health, especially those focused on psychology and considered in the development of this work, as well as unique characteristics of Fotossenti, with an assessment by specialist in psychology, and, finally, the challenges and opportunities found along the research. The conclusion recaps the importance of the development and use of new ICTs, particularly new information systems in the field of psychological health, and places the Fotossenti application as a tool to contribute to the generation of information for psychological treatment, and consequently the decisions taken by the therapist, increasing the benefits of treatment.

\section{Categorias e Descritores do Assunto}

H.4 [Information Systems Applications]: Miscellaneous; J.4 [Social and Behavioral Sciences]: Psychology

\section{Termos Gerais}

Design, Experimentation

\section{Keywords}

information system to support psychological treatment, picture oriented psychological treatment, m-health, e-health.

\section{INTRODUÇÃ̃}

O termo aplicativo sugere de forma simplista um software desenvolvido para ser instalado em um dispositivo eletrônico móvel (i.e. smartphone ou tablet), de uso fácil e interativo. O aplicativo desenvolvido, chamado de Fotossenti, supera essa ideia, atuando como um sistema de informação inovador em um ambiente de tratamento psicológico, em que se cria um novo canal de diálogo entre o paciente e o psicólogo de modo a viabilizar novas práticas terapêuticas na área.

As Tecnologias de Informação e Comunicação (TICs) voltadas à psicologia são comumente destinadas a informação, prevenção e tratamento de doenças de caráter psicológico e têm o intuito de complementar as abordagens tradicionais, criando novos mecanismos de interação entre paciente, psicologia e terapeuta. Deve-se ressaltar que as TICs não suprem e não tem o intuito de suprir a presença de um profissional, mas vêm de maneira a complementar as ações de determinada área. Para tornar real esse novo modelo ela deve ser 
usada como uma aliada no desenvolvimento das ações, e não com um possível olhar de rivalidade e concorrência.

Segundo Nicolaci-da-Costa e Leitão [5], os profissionais da psicologia, têm se voltado ao fato que a psicologia está mudando, ela deve se adequar a nova realidade do homem atual. A linha de atuação do aplicativo Fotossenti está junto a área comportamental da psicologia que dá ênfase às interações e emoções sentidas pelo paciente [19]. O objetivo é que o psicólogo comportamental adote juntamente com seu paciente o aplicativo como uma ferramenta auxiliar além dos métodos já aplicados no dia a dia da terapia.

A informatização da clínica psicológica traz grandes benefícios tanto para os usuários (pacientes) quanto para os profissionais (psicólogos) [6]. Com base nessa premissa foi proposto o aplicativo de captura de imagens e sentimentos para ser trabalhado junto com a psicologia comportamental. O Fotossenti dá ao psicólogo uma ferramenta a mais de auxilio no acompanhamento de seu paciente, e o paciente por outro lado vai se sentir mais próximo do seu psicólogo, pois mesmo o psicólogo estando longe, ele vai acompanhar remotamente seu paciente. Dessa forma, cria-se um novo canal de comunicação, por meio deste sistema de informação, entre o cliente e seu terapeuta.

O Fotossenti foi concebido como uma aplicação complementar à psicologia, informando situações ocorridas no dia a dia do paciente, que de alguma maneira possa passar despercebido, ou ser esquecido ou ainda não ter o devido valor atribuído pelo paciente, de modo que na seção com o psicólogo determinados fatos poderiam passar despercebidos. Em outra possível situação, o aplicativo pode ajudar em ocasiões em que o paciente não se comunicaria normalmente devido a aspectos como timidez, traumas, distúrbios fisiológicos etc. Este trabalho explorou a questão do beneficio a ser gerado pela implantação do aplicativo Fotossenti no tratamento terapêutico, até onde ele pode ser utilizado como uma ferramenta colaborativa no tratamento e quais as possíveis melhoras potenciais e reais que ele pode trazer para o tratamento. Junto à questão principal são abordadas questões secundarias como o quão aberto está a psicologia para este tipo de intervenção tecnológica e quais são os pontos de resistência a serem trabalhados para uma melhor inserção das TICs na psicologia. Também se avaliou o aplicativo como um novo modelo de geração de dados e complementação do tratamento terapêutico tradicional.

O restante deste artigo está organizado como segue: a seção 2 traz uma breve fundamentação teórica considerada neste trabalho, junto a uma pesquisa exploratória realizada para melhor habituação com a área da pesquisa; a seção 3 apresenta o aplicativo Fotossenti e suas particularidades; a seção 4 expõe avaliações sobre o Fotossenti e a seção 5 , por fim, aborda as considerações finais e trabalhos futuros.

\section{PROCEDIMENTOS METODOLÓGICOS}

\subsection{Fundamentação Teórica}

Contextualizando a evolução tecnológica a partir do olhar de Farah [11], a evolução do computador foi fruto da necessidade do ser humano aliado a uma nova demanda de serviços. Segundo Cosentino [4], inicialmente o computador sofria várias críticas como "[...] o homem se isolaria passando a interagir somente com as máquinas, afastando-se do convívio e meio social [...]", mas hoje em dia com o forte avanço da internet presencia-se que essas críticas são fracas, no mundo contemporâneo o computador tornou-se um meio de comunicação amplo e difundido entre várias camadas da população. Com base nessa inclusão o Fotossenti se encaixa como um meio de auxiliar a comunicação entre paciente e terapeuta de maneira a quebrar as barreiras impostas pelo consultório, sendo ampliada a comunicação paciente e terapeuta ao dia a dia, de maneira fácil, rápida e portavél.

Quando tratamos de aspectos de saúde abordados através de dispositivos móveis, segundo Morais et al. [8] estes podem ser classificados como em uma linha chamada de Mobile Health (ou mHealth / m-Saúde), eles podem estar presentes em vários momentos de tratamentos de saúde, desde a prevenção, diagnóstico e tratamento. O Fotossenti é um aplicativo dentro da vertente de m-Saúde responsável por gerar um fluxo de informação e ajudar no tratamento psicológico do paciente, melhorando o diagnóstico e dando mais informações sobre as ações a serem tomadas pelo psicólogo.

Dentro do contexto das TICs voltadas à psicologia, percebese que ela está num campo pouco explorado, onde consequentemente não são desenvolvidas tecnologias em escala significativa para atender o segmento de mercado psicológico e não refletindo a importância que essa vertente possui na área chamada e-Saúde. Assim este trabalho foi concebido buscando atender a carência de aplicativos sérios e sólidos presentes na informatização do tratamento psicológico.

Neste trabalho, trata-se a questão da fotografia como fundamental, dando sequência ao pensamento de Barthes [2] onde "o que a fotografia reproduz só ocorreu uma vez: ela repete mecanicamente o que nunca mais poderá repetir-se existencialmente", como as fotos são uma imagem direta e real trabalhadas junto a uma carga de informações passadas pelo aplicativo, estas imagens geradas podem exibir diversos fatores além do próprio objeto realmente fotografado. Dentre vários fatores que tornam o ato de fotografar propício para a análise, está a de que o sujeito é livre para fotografar o que quiser. Existe também a liberdade de tempo, pois se pode fotografar a qualquer hora, basta ter uma câmera; fotos são fotos, independentes do olhar artístico [18] (boas, ruins, fora de foco e etc.). Segundo Ramos [18] fotografias sempre transparecem algo, por isso são tiradas, cabe ao terapeuta detectar possíveis aspectos relevantes, conflitos e sentimentos inconscientes ou ainda identificar uma autoimagem idealizada ou aspectos de stress vividos pelo paciente.

$\mathrm{O}$ aplicativo apresentado antes de tudo levanta uma acirrada discussão de o quanto os sistemas de informação e a psicologia podem se relacionar. Um indício da conexão entre as áreas são as experiências vividas no Núcleo de Pesquisa da Psicologia em Informática PUC-SP [16], onde é trabalhado a Orientação Psicologia via e-mail, lá os contatos entre o paciente e terapeuta acontecem por meio de e-mails, facilitando a vida do paciente em várias maneiras como locomoção, tempo e dinheiro. Além de que através dos e-mails o paciente consegue se relacionar com franqueza com o seu terapeuta, atitude que talvez fosse dificultada em consultório. Segundo Nolf e Campos Novo [16] "[...] o que acontece é o virtual passando ao real, ou seja, possibilidades antes pertencentes ao possível e fantasmagórico mundo das possibilidades sendo atuado e questionado". Este trabalho ainda relata que o conteúdo do e-mail, percorre um caminho diferente do que as palavras tratadas num ambiente presencial. No meio virtual elas devem ser tratadas em sua gênese quanto a palavra escrita, onde essa palavra pode carregar muito mais do que o objeto em si, mas tam- 
bém uma carga de significados de sentimentos, emoções e aspectos sociais entre outros. O mesmo pode ser levado em conta no aplicativo Fotossenti, pois assim como a palavra, a imagem marcada é passível de várias interpretações cabendo ao terapeuta uma análise profunda para associa-la com a devida representatividade presente ao cotidiano de seu paciente. Assim a imagem junto com suas marcações são enviadas e geram um fluxo imenso de informações passando, como diz Nolf e Campos Novo [16], de possibilidade a realidade.

Para sabermos o quanto nossas vidas são permeadas pela tecnologia basta refletir que cada dia mais somos seres mais dependentes delas [4]. Outro fato que aponta essa inserção é que cada vez mais cedo as pessoas têm acesso às tecnologias. Quanto ao uso da internet e consequente interligação virtual entre pessoas, os números são positivos, segundo o Instituto Brasileiro de Geografia e Estatística ${ }^{1}$, entre o período de 2005 a 2011 o número de internautas cresceu $143,8 \%$ e o de pessoas com celular, 107,2\% recentemente em 2011 tínhamos 77,7 milhões de pessoas com 10 anos ou mais de idade (46,5\% do total) com acesso feito a internet nos três meses anteriores a pesquisa. O acesso a internet é maior nos grupos etários de 15 a 17 anos $(74,1 \%)$ e de 18 ou 19 anos de idade $(71,8 \%)$. Indicativo que no futuro estaremos norteados de jovens adultos usando um mar de aplicações móveis que utilizam a internet como meio, assim este trabalho explora esta tendência de crescimento global quanto às tecnologias móveis de comunicação voltadas à internet. Ainda vale ressaltar que em 2011, havia 115,4 milhões de pessoas de 10 anos ou mais de idade com telefone celular de uso próprio.

Com a crescente relação homem, computador e internet, abordadas no paragrafo anterior, o esforço cognitivo para lidar com aplicações on-line vai sendo reduzido, e já é percebido com mais naturalidade por uma parcela da população. Reforçando esta afirmação, Joly [13] afirma que com a constante presença da tecnologia na vida das pessoas para realizações de tarefas diárias, nota-se uma crescente e rápida adaptação do ser humano com as tecnologias da comunicação e informação. Nicolaci-da-Costa e Leitão [5] fazem ligação deste fenômeno com a psicologia ressaltando essa aproximação da psicologia clínica com a informática. Assim o aplicativo desenvolvido vem justamente na tentativa de aproximar a tecnologia da psicologia de forma mais natural.

Outros aspectos devem ser abordados, afirma Limonge [14], onde já existe por parte do Conselho Federal de Psicologia uma atenção ao que diz respeito a tecnologias que influenciam as relações humanas. Em seu artigo [14] é trabalhado que para compreender melhor a participação da informática na iteração humana, deve-se pensar em uma escala evolutiva para se tentar prever o comportamento que ainda está por vir, onde as descobertas tecnológicas vêm para suprir fins práticos do quotidiano do ser humano. Essa adaptação se torna determinante para cada vez mais desenvolver-se instrumentos informatizados para auxiliar diversas áreas.

Segundo Olea e Hontangas [17], deve-se ressaltar também que o crescente avanço do uso da tecnologia computacional propicia à psicologia melhores condições de teste com instrumentos informatizados. Mas ainda existem vários pontos desestimulantes no uso das TICs na psicologia, como apon-

\footnotetext{
${ }^{1}$ Pesquisa IBGE/PNAD sobre acesso a internet e posse de telefone móvel celular para uso pessoal de 2011. http://www.ibge.gov.br/home/estatistica/populacao/ acessoainternet2011/default.shtm.
}

tado por Alves et al. [1] onde é classificado como "irrisório" o estudo e aplicação de testes informatizados nos cursos de graduação em psicologia, fato detectado em sua pesquisa em mais de 62 universidades do pais.

A ação a ser realizada com o uso do aplicativo proposto inicia-se com o paciente e com o conteúdo da imagem a ser passada. Cabe ao terapeuta estar ciente de todo conteúdo passado para depois introduzi-lo na terapia. Esse método rompe em parte com o modelo de linhas rígidas de Freud que coloca o uso do divã [12]. Neste modelo diferenciado o aplicativo Fotossenti trabalha em um processo de uso aberto pelo lado do paciente, paralelo a uma avaliação controlada feita pelo terapeuta, onde os dados são livremente gerados, rotulados com os recursos do aplicativo pelo paciente e postados, do outro lado é essencial a figura de um terapeuta para realizar a análise das informações passadas. Explora-se a atuação numa linha de extensão controlada do relacionamento paciente e terapeuta com o intermédio da tecnologia. Essa nova tecnologia traz ao terapeuta uma nova vertente de trabalho, pois serão geradas informações que poderiam não ser ditas dentro do consultório ou ainda passarem despercebidas.

Um aspecto importantíssimo, relacionado ao desenvolvimento de aplicativos é o chamado custo de resposta onde, segundo Carreiro [3], este termo relaciona-se ao tempo levado para realizar determinada ação. Caso o tempo seja elevado este fator é um desencorajante forte para a não aceitação da realização de determinada tarefa. Para se produzir determinado benefício ao tratamento, é preciso antes de tudo que a ferramenta tenha um custo de resposta baixo [3], sendo este um fator crucial para uma boa aceitação por parte dos usuários. Abordando a ferramenta proposta, o aplicativo Fotossenti, deve-se ter em mente que ela irá trazer uma tarefa a mais para o terapeuta executar, que dependendo do profissional pode gerar um empecilho. Fazendo uma reflexão a respeito da postura do psicólogo sobre essa nova realidade Fortim [12] coloca que esse profissional pode ter duas posturas bem distintas, os chamados românticos, que são reticentes a adoção de tecnologias, e os entusiastas, que são os que fortemente irão aderir a essa vertente. Ainda segundo Fortim [12] a maioria dos psicólogos se veem no perfil romântico da sua formação, sendo bastantes conservadores, colocando o contato face a face como único no tratamento psicológico. Já os entusiastas, em menor porção, veem com bons olhos a relação psicologia e tecnologia, pois para eles tudo o que pode vir a acrescentar só tende a melhorar o tratamento do paciente. Pelo lado do paciente (cliente), também existe um custo de resposta, pois ele necessita de um smartphone, e possuir uma conexão mesmo que esporádica com a internet, para que em algum momento seja feito a transmissão das imagens para o repositório virtual.

\subsection{Pesquisa Exploratória}

$\mathrm{O}$ uso das TICs voltada à psicologia é um campo ainda pouco estudado [1], assim para um melhor entendimento da área foi aplicada uma pesquisa exploratória, que teve como objetivo reunir aspectos da área, e consequentemente buscar maior compreensão sobre esta vertente da e-saúde. Como passo inicial para o desenvolvimento da pesquisa, partimos da intuição de que existe sim, espaço para a tecnologia atuando junto ao tratamento psicológico e que este espaço está aberto para um novo aplicativo móvel. A pesquisa exploratória foi feita para tentar responder às seguintes perguntas: 


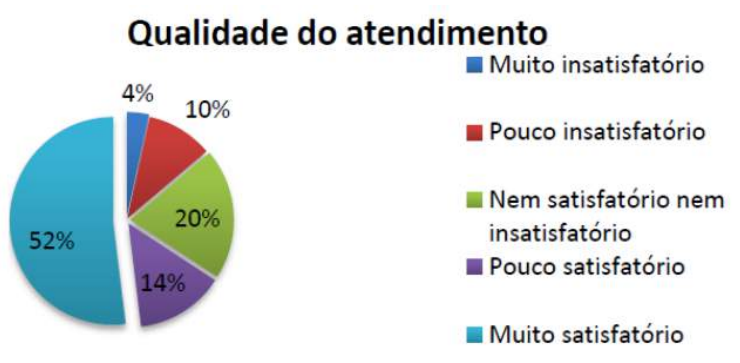

Figura 1: Percentual da qualidade do atendimento(tratamento) percebida pelo paciente.

\section{Possibilidade de novas tecnologias para lidar com o psicólogo ou a psicologia}

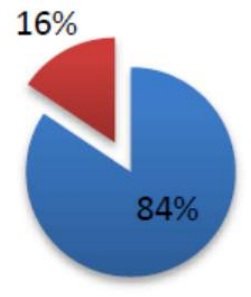

\section{@ Sim $\quad$ Não}

Figura 2: Percentual de respondentes que veem com bons olhos a possibilidade de novas tecnologias interagindo com a psicologia.

- O que o paciente acha do uso de novas tecnologias que propiciem uma melhor comunicação com o psicólogo ou melhor entendimento de aspectos da psicologia?

- Caso seja desenvolvido um aplicativo móvel baseado em fotos, você o adotaria, para melhorar sua interação com seu psicólogo?

O público alvo da pesquisa é constituído de pessoas que fazem ou já fizeram tratamento psicológico, mesmo que este se resuma a uma única consulta na clínica. As idades e camadas sociais não são critérios excludentes do respondente, onde estes são tratados de forma igualitária.

Foi usado o formato de questionário online, por ser de fácil aplicabilidade, difusão e tabulação dos dados, este método ainda possui a característica de reunir informações que podem não ser absorvidas em um modelo de prospecção de forma presencial, pois em alguns casos o entrevistado pode se sentir coagido ou mesmo acuado por fatores externos. A divulgação da pesquisa foi realizada por meio de mídias sociais na Internet, enfatizando a divulgação nas comunidades virtuais da instituição de ensino onde a pesquisa foi aplicada.

A pesquisa versou de um conjunto de questões mistas (algumas abertas e outras fechadas). Algumas das questões fechadas estão no formato da escala de Likert [9], que se baseia "na premissa de que a atitude geral se remete às crenças sobre o objeto da atitude [...]". Outras questões seguem o modelo de escala nominal. Segundo Mattar [15] "uma escala nominal é aquela em que os números servem apenas para nomear, identificar e (ou) categorizar dados sobre pessoas, objetos ou fatos".

O questionário teve 48 respondentes, número entendido como bom, pois eles ficaram livres para responder ou não a pesquisa, sendo que também poderiam a qualquer momento cessar sua participação. Com essa liberdade enfatizada, o nível de significância das respostas pode ser considerado alto e fidedigno, pois se a pessoa se prontificou espontaneamente a responder sem nenhuma obrigatoriedade, infere-se sua sinceridade sobre as respostas. Os respondentes são anônimos e não foram oferecidas gratificações além do ato de estar ajudando a desenvolver a área. Assim mais uma vez pode-se deduzir que as respostas foram dadas por motivação essencial de ajuda e esclarecimento.

No geral obtivemos $56 \%$ de respondentes declarados homens e $44 \%$ mulheres sendo que a maioria estava na faixa etária entre 20 e 24 anos (56\%), 15 e 19 anos (11\%), 25 e 29 anos (27\%), consolidando $67 \%$ na faixa de 15 a 24 anos. Refletindo uma correlação entre os dados coletados tem-se uma percepção de que a aceitação de uma tecnologia para a faixa 15-24 anos hoje implicará que no futuro tecnologias similares irão ser bem aceitas por um público mais maduro.

Quando o abordado foi o nível de satisfação da consulta ou tratamento psicológico percebida pelo paciente, o parâmetro mais referenciado foi "muito satisfatório", mas por outro lado avaliando a estrutura gerada, percebe-se que ao se tratar da excelência no atendimento quase metade dos respondentes ainda acha que algo pode ser melhorado, deixando uma abertura para melhoras no tratamento, como exemplificado nos dados demonstrados na figura 1 .

Visando melhor atender essa parcela que ainda sente falta de uma excelência em seu tratamento, pode-se considerar o uso de novas TICs voltadas à psicologia, em especial no uso de novas tecnologias para melhorar a relação entre paciente e psicólogo. Esta constatação fica evidenciada pela aprovação do uso de novas tecnologias interagindo com a psicologia mostradas na figura 2 .

Dando continuidade à avaliação do tratamento psicológico, para melhor entendermos as necessidades de um aplicativo nessa área, foi questionado o que uma pessoa espera do tratamento com um psicólogo. Dentre as várias respostas obtidas, destacam-se (palavras dos respondentes):

- "Sigilo e confidencialidade das informações", em alguns casos percebe-se que pessoas sentem-se retraídas por não ter certeza destes aspectos.

- "Auxilio e orientação em problemas vividos."

- "Intervenções perspicazes e úteis no tratamento."

- "Que saiba deixar o paciente se expressar de maneira fluida, mas conduzindo o diálogo."

- "Saber interpretar o que às vezes não consigo falar".

- A ajudar a "reorganizar minha vida".

Durante o questionário ainda foi perguntado qual o sentimento da pessoa sobre seu atendimento com o psicólogo, o que ela achou do tratamento. Esta questão foi feita de modo a dar ao respondente liberdade total na sua colocação. Feita uma análise, dentre as vàrias respostas, destaca-se:

- O psicólogo "não deve transparecer seus juízos sobre os seus pacientes." (linha: Psicanálise)

- "A psicologia é fascinante, porém há profissionais bastante despreparados." (não informou linha) 
- "Não satisfação com resultados obtidos."(não informou linha)

- Algumas vezes o psicólogo não deixava a pessoa expressarse "esclarecer a situação [...]".(linha: Psicanálise)

- "Esperava atendimento mais minucioso." (linha: Psicanálise)

- "Minha relação com os psicólogos com os quais fui atendido foi boa mas aquém de minhas expectativas." (linha: Psicologia Analítica)

- "Sou muito critica quanto ao exercício da profissão e por isso pelos profissionais que já passei sempre teve algo na pratica dos mesmos que achei incoerente e até antiético." (linha: Psicologia Humanista)

- "[... sentia a necessidade de um tratamento que fosse mais integral e continuado, mas acabaria por tratar de questões que iriam para além das questões centrais daquele (sexo, uso de camisinha, doenças, etc) [...]." (linha: Psicanálise)

- "As vezes é monótona, as técnicas são muito antigas, acho que deveriam se atualizar." (não sabe a linha)

- "[...] sinto a necessidade de novos campos, e investimento em campos alternativos como a Psicologia Transpessoal."(linha: Arte Terapia baseada no Jung)

- "[...] atende minhas expectativas em relação a algumas maneiras de conduzir e reorganizar meus comportamentos [...]." (linha: Cognitivo comportamental)

Percebe-se que em vários casos o paciente almeja algo diferente em seu tratamento e algumas vezes foi citado aspectos relativos a métodos que não se encaixam com a pessoa. Em alguns desses casos acreditamos que esse algo mais possa ser uma nova maneira de se relacionar com o psicólogo, referenciando Nicolaci-da-Costa e Leitão [5], as pessoas assim como o mundo estão mudando e tem anseios diferentes dos que tinham a décadas atrás.

A última pergunta feita está relacionada com a proposta deste trabalho, em que se questiona se o paciente (independente da linha de seu terapeuta, estado atual de tratamento e etc.) vê com bons olhos um aplicativo de fotos para ajudar (ficando claro "não substituir") o tratamento psicológico vivenciado por ele. Uma grande maioria de $84 \%$ opinou que sim, a iniciativa poderia gerar bons resultados.

Pela pesquisa exploratória, percebe-se que é necessário inovar nesta área e o aplicativo proposto pode possuir uma boa taxa de aceitação, visto que os fundamentos da proposta agrada a grande maioria dos pesquisados. Esta constatação reforça nosso trabalho de aproximação no desenvolvimento de TICs com a psicologia, e consequente inserção do aplicativo Fotossenti no auxilio ao tratamento psicológico.

\section{O APLICATIVO FOTOSSENTI}

Segundo Estrázulas [10], o desenvolvimento de aplicações como meio de proliferação da tecnologia é inerente aos seres humanos e sua aprovação também, tudo isso faz parte da sua cultura que se altera com o passar do tempo. Nas palavras de Estrázulas [10] “ [...] é necessário ter claro que a tecnologia impulsiona transformações culturais, mas não as

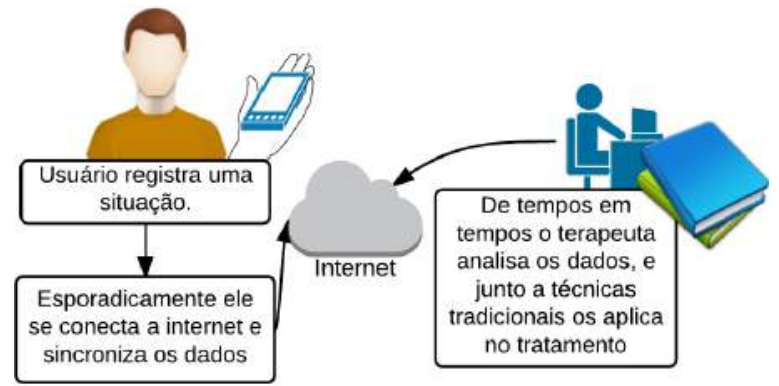

Figura 3: Arquitetura de tecnologia do funcionamento do aplicativo Fotossenti.

contém, entretanto em sua totalidade. Isto significa que serão os indivíduos os legítimos responsáveis pela apropriação critica e emancipatória do uso de instrumentos digitais informacionais [...]". O desenvolvimento do aplicativo proposto foi pensado a partir dos anseios de usuários da tecnologia, tentando sempre minimizar o custo de resposta para efetuar as ações, adequando-se ao proposto por Carreiro [3], e maximizar a geração de informação e comunicação de forma a ocasionar benefícios no tratamento do paciente.

A essência do aplicativo é usar a câmera fotográfica do aparelho móvel como uma lente que irá captar as características do estado de humor do usuário. Imagina-se que em seu tratamento o usuário deverá ao menos uma vez por dia tirar uma foto de um objeto, ação ou situação, enfim algo que o interesse e que ele coloque como sendo marcante em seu dia. Junto com a foto ele irá informar o nível de humor que ele está naquele momento e outras informações sobre o que está sentindo. Todavia, a prescrição do modo de uso a ferramenta é mais bem definida pelo próprio terapeuta e adequada ao tratamento e intervenção desejada.

O Fotossenti, trabalha em um novo arquétipo de comunicação, sua proposta é pioneira, onde não foram encontrados nenhum modelo de TICs similar no mercado. A proposta inicial foi feita utilizando o Dropobox para comunicação, mas nada impede que esses dados sejam compartilhados por e-mail ou por outro repositório que esteja instalado no celular, como Google Drive. Mais detalhes de como essa iteração acontece pode ser vista na figura 3 .

Conforme o trabalho de Cunha [7], com uma análise bem feita do comportamento, pode se identificar situações que levam o paciente a tomar determinada atitude. Essas situações se comportam como um gatilho que irá gerar um comportamento específico, com o comportamento identificado pode-se instruir ao paciente sobre este aspecto, essas ações são os chamados gatilhos emocionais. A proposta do aplicativo é estabelecer um novo modelo de interação, de modo a permitir as pessoas a expressar seus sentimentos através de imagens com um custo de resposta baixo.

A cada utilização, ou quando existir conectividade adequada, o aplicativo enviará automaticamente as informações geradas pelo aplicativo a uma base de dados online, onde o psicólogo tem acesso remoto imediato, independente da hora e local em que está bastando para isso se conectar internet. Assim o psicólogo terá uma carga maior de informações para fazer uma análise do comportamento de seu paciente e tentar identificar possíveis transtornos.

Da forma como o sistema foi implementado, o psicólogo 


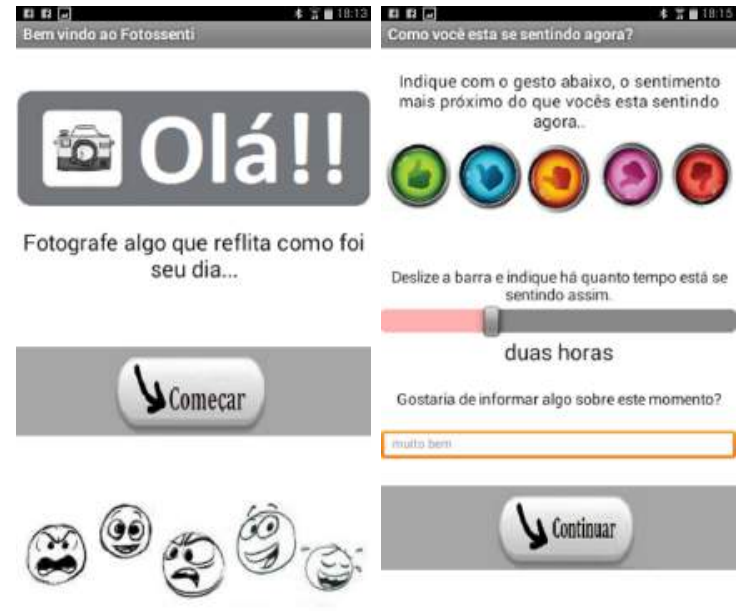

Figura 4: A esquerda (a) abertura do aplicativo, a direita (b) tela de inserção de dados dos sentimentos, a direita.

necessita apenas de um computador (desktop, notebook, ultrabook etc.) com acesso ao Dropbox ${ }^{2}$ instalado e com conexão esporádica a internet. Já o paciente necessita de um smartphone sistema operacional Android para executar o aplicativo. O protótipo do aplicativo Fotossenti foi implementado utilizando o ambiente de desenvolvimento MIT App Inventor $2^{3}$, que gera aplicações para o ambiente Android. O paciente deverá ter uma versão do aplicativo Fotossenti instalada em seu smartphone ou tablet Android juntamente com o Dropbox e conexão com à internet. Tanto o psicólogo quanto o paciente não precisam estar conectados constantemente a internet, basta uma conexão esporádica para sincronizar os dados.

A configuração do sistema requer que o paciente tenha uma pasta compartilhada com seu psicólogo, onde serão registradas as informações geradas pelo aplicativo, para serem trabalhadas na sua consulta. Com o passar do tempo, quando o paciente for rever seu psicólogo em uma nova consulta física de seu tratamento, ambos terão um material a mais a ser trabalhado. A adoção do uso do aplicativo deve partir de ambos os lados, onde tanto o psicólogo quanto o paciente devem estar de acordo com o uso da tecnologia.

Ao instalar o Fotossenti em seu aparelho móvel Android, na tela inicial irá ser criado um ícone, o mesmo deve ser tocado para inicializar o aplicativo. A tela inicial é simples, figura 4(a), servindo para mostrar ao usuário a abertura e inicio da aplicação. Subsequentemente, será aberta a câmera fotográfica do dispositivo, na parte superior da tela e o usuário poderá alterar as configurações de câmera se necessário e deverá tirar uma foto normalmente. A foto deve ser de qualquer ação ou objeto que ele queira para representar seu sentimento naquele momento. O tema da foto é livre para o usuário.

A próxima tela, mostrada na figura 4(b), é para inserção de dados sobre a foto, começando com a seleção de um gesto de como você se sente no momento, para isto você deve

\footnotetext{
${ }^{2}$ Trata-se de um serviço de compartilhamento de arquivos na rede, disponível em: https://www.dropbox.com/

${ }^{3} \mathrm{http}: / /$ appinventor.mit.edu/explore/
}
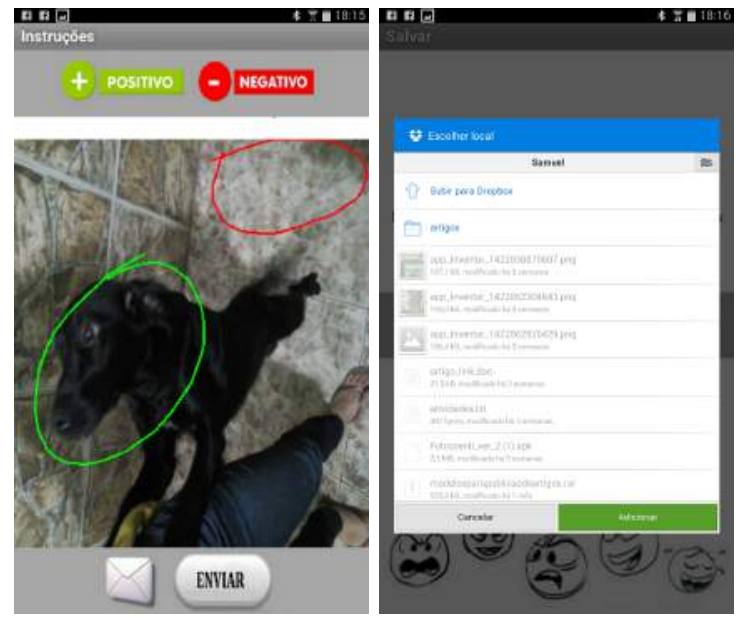

Figura 5: A esquerda (a) tela de marcar características na foto e salvar, a direita (b) a tela de compartilhamento dos dados gerados.

escolher um dos 5 gestos mostrados na tela, depois o usuário deve deslizar um ponteiro para indicar a quanto tempo se sente daquela maneira e por fim o usuário é livre para gerar dados adicionais que queira informar a seu terapeuta. Essas informações adicionais são de carácter complementar, se o usuário não quiser informa-las não há problema, elas servem para enriquecer a informação a ser passada.

Após, na tela mostrada na figura 5(a), o usuário deverá marcar as características positivas ou negativas presentes na imagem que ele fotografou. Após esta ação ele deve clicar em enviar, caso tenha marcado errado basta balançar o dispositivo para apagar as marcações. Subsequentemente na tela da figura 5(b) o usuário deverá indicar salvamento dos dados gerados em uma pasta conjunta entre o paciente e seu terapeuta no Dropbox.

Não é necessário estar conectado a internet a todo tempo, caso não haja rede no momento, os dados ficarão guardados na memória do aparelho, para que em algum momento, quando o usuário for conectar o celular, os dados então serão automaticamente sincronizados. Esta funcionalidade é provida pelo Dropbox.

\section{AVALIAÇÃO}

\subsection{Avaliação dos pesquisados}

Considerando os participantes da pesquisa exploratória, em especial os que se propuseram a participar de uma pesquisa futura e declararam que veem com bons olhos o uso de novas tecnologias empregadas junto a psicologia, foi pedido uma opinião aberta sobre o aplicativo Fotossenti. Entre as várias respostas dos 25 participantes podemos destacar os seguintes comentários:

- "Acredito que imagens podem ajudar na rememoração de fatos e de sentimentos que ocorreram no momento em que a foto foi capturada." (linha: Psicanálise)

- "Sim porque tem objetos, imagens e situações que muitas vezes nos incomodam ou chamam a atenção constantemente e cabe trabalhar isto na clinica, entender 
o significado, o porquê do incomodo e etc."(linha: Psicologia Humanista).

- "Acho que nada melhor do que retratar o seu dia, ou algo que te chamou a atenção para se entender." (linha: Abordagem Centrada na Pessoa).

- "[...] poderia justificar/incentivar e motivar o relato. Apoiando o tratamento." (não sabe a linha usada)

- "[...] para o psicólogo ver o ambiente em que a pessoa vive, tal como a visão que ela tem de mundo." (linha: Abordagem Centrada na Pessoa)

- "Qualquer aplicativo que possibilite conhecer melhor o contexto ajudaria bastante na analise e intervenção." (não informou linha)

- "Estar documentado para um diagnóstico mais correto." (não informou linha)

- "Seria uma forma de mostrar a ele pontos marcantes do meu dia [...]" (linha: Arte Terapia baseada no Jung)

- "[...] poderia ajudar mais rapidamente em processos de cura interior". (não sabe a linha usada)

- "Dependendo da abordagem, poderia ajudar sim... mas acredito que muito mais do que o objeto, deve-se levar em conta a relação do sujeito com esse objeto [...]." (não sabe a linha usada)

- "Auxiliaria ao arquivar coisas importantes do paciente para ajudar no trabalho do psicólogo." (linha: Cognitivo comportamental)

\subsection{Avaliação por especialista}

No dia 20 de novembro de 2014 foi feita uma reunião com o Dr. Diogo Antônio Bloes Chagas ${ }^{4}$. A conversa iniciou-se com a fundamentação sobre o conceito chamado custo de resposta, segundo Dr. Diogo, este termo relaciona-se ao tempo levado para realizar determinada ação. Caso o tempo seja elevado este fator é um desencorajante para a não aceitação da realização de determinada tarefa. Segundo a entrevista, para se produzir determinado benefício, é preciso antes de tudo que a ferramenta tenha um custo de resposta baixo, fator que segundo o entrevistado é crucial para uma boa aceitação por parte dos usuários. Abordando a ferramenta Fotossenti, deve-se ter em mente que ela irá trazer uma tarefa a mais para o terapeuta executar, que dependendo do profissional pode gerar um empecilho.

Para o entrevistado, com o custo de resposta baixo, a proposta é uma ação "extremamente válida e promissora", onde ele acredita que o futuro da psicologia vai estar envolvido em ações que utilizam o meio virtual para o relacionamento. Tal característica é extremamente promissora por vários fatores, que giram em torno do custo de resposta, como, deslocar-se em um grande centro para uma consulta, trânsito, tempo, dinheiro etc.; ou caso o paciente esteja viajando e necessite de uma interação com seu terapeuta; ou ainda caso esteja doente e o terapeuta não possa atendê-lo em casa. Todos

${ }^{4}$ Mestre e Doutor em Psicobiologia pelo Departamento de Psicologia da Universidade de São Paulo em Ribeirão Preto. Especialista em clínica analítico-comportamental pelo Paradigma: Núcleo de Análise do Comportamento - SP. esses são exemplos de custo de resposta alto que podem inviabilizar a consulta terapêutica de uma pessoa pelos meios tradicionais, mas que de alguma forma podem ser contornados pelo uso das tecnologias da informação.

A aplicação proposta é válida como um complemento à psicologia em pontos específicos, informando ações do dia a dia do paciente, que de alguma maneira possam passar despercebidos, ou serem esquecidos ou ainda não terem o devido valor atribuído pelo paciente, de modo que na seção com o psicólogo estes aspectos poderiam não ser notados. Assim o terapeuta poderá abordar situações em que o paciente não falaria normalmente.

A ideia da ferramenta é boa no sentido da anotação para uma análise feita juntamente com o terapeuta, onde "é bom o cliente estar produzindo dados no momento em que não é o do atendimento". Muitas vezes o cliente não se solta na terapia, e para tentar melhorar a interação é pedido a ele para realizar certas atividades e depois as descrever, neste caso o aplicativo também pode ser inserido. Outro aspecto importante é identificar de maneira real o que acontece no mundo do paciente o que favorece determinada ação, lembrando que a imagem traz uma identificação fidedigna do momento, assim o uso do "recurso visual é ótimo" para explorar melhor a situação e dar ao terapeuta mais informações sobre como o tratamento deve ser continuado.

O uso do recurso visual é ideal para explorar melhor a situação e dar ao terapeuta mais informações sobre como o tratamento deve ser continuado, obtendo também dados importantes que podem ser fonte inovadora de abordagens futuras no tratamento. O recurso de marcar o que o cliente acha de determinada ação com pontos nas fotos e linhas vermelhas e verdes é bom, pois dá ao cliente uma maneira de informar o que ele acha de determinada ação com mais liberdade. É válido também o uso das tags informativas, figura 4(b), pois quanto mais informações o usuário quiser passar melhor, e caberá ao terapeuta dar o valor a essas informações. A barra de sentimento gradual com os sinais de sentindo-se muito bem até sentindo-se muito mal foi uma boa ideia para o aplicativo, pois traz uma maneira diferente para o usuário expressar-se sem usar palavras. Segundo o especialista a linha de avaliação é uma estratégia muito boa e muito usada na clínica terapêutica. Durante toda a entrevista foi sempre frisado que é muito importante estar produzindo dados sobre algo que não iria ser percebido, neste ponto o aplicativo é fundamental, pois ele origina dados fidedignos e espontâneos por parte do paciente.

Para o especialista o fato de que as imagens não sejam enviadas em tempo real, caso o usuário possua internet de maneira esporádica, não é um empecilho, pois não existe a necessidade das informações serem repassadas instantaneamente. O fundamental é que as imagens persistam, e que não se percam, deixando o fator da instantaneidade de lado e priorizando a confiabilidade.

Foram abordados aspectos na entrevista em que a psicologia utiliza de forma massiva a classificação do comportamento do sujeito o que acaba omitindo informações que podem ser úteis. Dentre outros aspectos, uma das principais contribuições se dão pelo fato de se estar efetuando uma etapa do tratamento psicológico, de forma não presencial, onde juntamente com uma linha de atendimento virtual é uma grande tendência, pois se pode gerar e obter aspectos mais precisos e eficazes para fomentar a terapia e ajudar a psicologia clínica a oferecer um melhor tratamento. 


\section{CONCLUSÃO}

Considerando os resultados iniciais da pesquisa bibliográfica e pesquisa exploratória, ficou evidente a necessidade de inovar no desenvolvimento de TICs, em especial no desenvolvimento de novos sistemas de informação, com aplicação na área de psicologia. O uso de aplicativos móveis é tendência tecnológica e possui grande aceitação de acordo com a pesquisa realizada. Portanto, a proposta deste trabalho, o aplicativo Fotossenti atua numa linha promissora com o desenvolvimento de sistemas de informação inovadores voltados a e-saúde, agregando valor ao tratamento psicológico convencional, permitindo que o terapeuta obtenha informações sobre o cotidiano de seu paciente de maneira externa aos métodos tradicionais.

O modelo de interação aqui proposto cria uma liberdade bem maior não só para o paciente, mas também para o psicólogo, pois o mesmo pode trabalhar com informações geradas fora do consultório físico, o que pode guiar melhor o tratamento com base nas novas informações disponíveis. Ainda calcado pela análise do especialista, vislumbramos que brevemente o futuro da psicologia vai estar envolvido em ações que utilizam o meio virtual para interações terapêuticas. O aplicativo Fotossenti foi desenvolvido para atuar neste campo e possui um conjunto de características extremamente promissoras por vários fatores que giram em torno do baixo custo de resposta e liberdades de tempo, localização e sentimento.

Os esforços atuais na continuação de desenvolvimento deste trabalho estão em relação à legitimidade da informação gerada e o custo de reposta desse novo modelo de interação. Estes são os aspectos fundamentais adotados pela filosofia inserida no Fotossenti, que com base na pesquisa exploratória e bibliográfica são colocados como primários para a adoção dessa nova tecnologia.

Como trabalho futuro propõe-se uma avaliação considerando a prática em uma clínica a fim de analisar a utilidade e prospectar funcionalidades que possam ser incluídas ou modificadas. Outros trabalhos podem ser desenvolvidos considerando a temática apresentada neste artigo. Neste artigo apresentou-se uma ferramenta inovadora que esperamos servir também de inspiração para a criação de várias outras para que possam ser utilizadas como novas ferramentas viabilizando novas intervenções terapêuticas.

\section{AGRADECIMENTOS}

A Universidade Federal de São João del Rei (UFSJ), pelo apoio institucional e financeiro para a realização e apresentação deste trabalho.

\section{REFERÊNCIAS}

[1] I. C. B. Alvea, J. C. Alchieri, and K. C. Marques. As técnicas de exame psicológico ensinadas nos cursos de graduação de acordo com os professores. Psico USF, 1(7):77-88, Junho 2002.

[2] R. Barthes. A câmara clara: nota sobre a fotografia. Editora Nova Fronteira, Rio de Janeiro, 1984.

[3] P. L. Carreiro. O efeitos da probabilidade de reforçamento e do custo da resposta sobre a persistência comportamental. Mestrado, Universidade de Brasília, UNB, 2007.

[4] L. Cosentino. Aspectos evolutivos da integração homem maquina: Tecnologia, computador e evolução humana. Psicologia 63 Informática: Produções do III PSICOINFO e II Jornada do NPPI, pages 61-71, 2006.

[5] A. M. N. da Costa and C. F. Leitão. Impacto da internet sobre pacientes: A visão de psicoterapeutas. Psicol. estud., 10:441-450, Dezembro 2005.

[6] A. M. N. da Costa, A. P. C. Santos, E. Herzber, F. T. Maiorino, I. F. Campos, J. Z. JOSÉ JORGE DE MORAES Zacharias, M. R. S. LIA Pitliluk, O. Z. Prado, P. G. S. Filho, R. S. G. F. Nascimento, and S. B. Meyer. Psicologia e Informática: Desenvolvimentos e Progressos. Casa do Psicólogo, Rio de Janeiro, 2005.

[7] A. C. B. da Cunha. Análise experimental do comportamento. Psicoterapia comportamental e cognitiva: pesquisa, prática, aplicações e problemas, pages $15-25,1998$.

[8] D. C. S. de Morais, B. C. S. de Morais, J. V. deMenezes Júnior, and C. M. G. de Gusmão. Sistema móvel de apoio a decisão médica aplicado ao diagnóstico de asma - intelimed. VIII Simpósio Brasileiro de Sistemas de Informação (SBSI 2012), Trilhas Técnicas, 2012.

[9] T. M. V. de Oliveira. Escalas de mensuração de atitudes: Thurstone, osgood, stapel, likert,guttman, alpert.

http://www.fecap.br/adm_online/art22/tania.htm, 2001. [Online; accessed 15-setembro-2014].

[10] M. Estrázulas. Interação e sócio-cognição na internet : A teoria do desenvolvimento sócio-cognitivo no estudo das trocas entre crianças na escola e fora da escola. Mestrado, Instituto de Psicologia, UFRGS, 1997.

[11] R. M. Farah. Psicologia e Informática: O ser humano diante de novas tecnologias. Editora Oficina do Livro, São Paulo, 2004.

[12] I. Fortim. O orkut na clínica e a relação terapeuta paciente. Psicologia 6 Informática: Produções do III PSICOINFO e II Jornada do NPPI, pages 48-60, 2006.

[13] M. C. R. A. Joly. Sistema de avaliação psicológica informatizada. Psicologia \& Informática: Produções do III PSICOINFO e II Jornada do NPPI, pages 152-160, 2006.

[14] N. Limonge. Testes informatizados - uma nova visão. Psicologia 8 Informática: Produções do III PSICOINFO e II Jornada do NPPI, pages 285-292, 2006.

[15] F. N. Mattar. Pesquisa de marketing: metodologia e planejamento. Editora Altas, São Paulo, 1999.

[16] A. Nolf and L. de Campos Novo. Orientação psicologia via e-mail do nppi. Psicologia E Informática: Produções do III PSICOINFO e II Jornada do NPPI, pages 162-168, 2006.

[17] J. Olea and P. Hontangas. Testes informatizados de primera generación. Testes informatizados: fundamentos y aplicaciones, pages 23-52, 1999.

[18] M. M. Ramos. Fotografia e arte: Demarcando fronteiras. Revista Conteporânea, (12):129-142, 2009.

[19] B. Rangé. Psicoterapia comportamental e cognitiva: pesquisa, prática, aplicações e problemas. Editora Psy, 1998. 